05

\title{
Эволюция ударных волн в горячепрессованных керамиках карбида бора и карбида кремния
}

\author{
() А.С. Савиных, ${ }^{1,2}$ И.А. Черепанов, ${ }^{3}$ С.В. Разоренов, ${ }^{1,2}$ А.И. Овсиенко, ${ }^{4}$ В.И. Румянцев, ${ }^{4}$ С.С. Орданьян ${ }^{5}$ \\ ${ }^{1}$ Институт проблем химической фризики РАН, \\ 142432 Черноголовка, Россия \\ ${ }^{2}$ Национальный исследовательский Томский государственный университет, \\ 634050 Томск, Россия \\ ${ }^{3}$ Московский государственный университет им. М.В. Ломоносова, \\ 119991 Москва, Россия \\ ${ }^{4}$ ООО ВИРИАЛ, \\ 194156 Санкт-Петербург, Россия \\ ${ }^{5}$ Санкт-Петербургский государственный технологический институт (технический университет), \\ 190013 Санкт-Петербург, Россия \\ e-mail: savas@ficp.ac.ru
}

(Поступило в Редакцию 23 марта 2018 г.)

С целью определения возможного вклада релаксационных процессов в сопротивление высокоскоростному деформированию проведены измерения эволюции волн ударного сжатия в горячепрессованных керамиках из карбида бора и карбида кремния при максимальном напряжении сжатия 32 и $34 \mathrm{GPa}$ соответственно. При изменении толщины образцов от 0.5 до $8 \mathrm{~mm}$ выявлено заметное затухание упругого предвестника у карбида бора, в то время как в экспериментах с образцами карбида кремния разной толщины наблюдается незначительный аномальный рост упругого предвестника с толщиной образца. Измеренное значение динамического предела упругости образцов толщиной $8 \mathrm{~mm}$ у карбида кремния составило $\sigma_{\mathrm{HEL}}=15 \pm 0.1 \mathrm{GPa}$, для карбида бора $\sigma_{\mathrm{HEL}}=17.2 \pm 1.3 \mathrm{GPa}$.

DOI: $10.21883 / J T F .2018 .12 .46782 .38-18$

\section{Введение}

В наиболее широком смысле керамика - это изделия, полученные путем спекания прессовок из порошков исходных веществ или материалов на их основе при температуре существенно ниже температуры плавления (размягчения, разложения, сублимации) этих веществ или материалов. Именно поэтому в керамике можно использовать наиболее широкий спектр композиционных материалов, компоненты которых могут значительно отличаться по своему составу и свойствам, а полученные изделия обладать принципиально новыми свойствами, которые не являются свойствами простой суммы компонентов [1]. Во многих областях промышленности изделия из высокотвердой керамики используются в условиях, сопряженных с интенсивными ударными воздействиями микросекундной длительности. В силу дороговизны сложных керамических изделий актуальным становится прогнозирование результатов ударных воздействий методами компьютерного моделирования. Для построения адекватных моделей и определяющих соотношений, описывающих сопротивление высокоскоростному деформированию и разрушению в условиях высокоскоростного удара, в частности, необходимо правильно оценить вклад релаксации напряжений в этом временном диапазоне [2].

Исследования эволюции волны сжатия по мере ее распространения в металлах и сплавах обычно де- монстрируют затухание упругих предвестников ударных волн, анализ которого дает сведения о начальной скорости релаксации напряжений и соответствующей скорости пластической деформации. Так, например, особенностью упругопластического перехода в ванадии [3] при ударно-волновом нагружении является ярко выраженная область быстрой релаксации напряжений за фронтом упругого предвестника. Выход фронта упругой волны сжатия на поверхность образца сопровождается формированием за фронтом упругого предвестника ниспадающего профиля - „зуба текучести“, что традиционно связывается с интенсивным размножением дефектов дислокационного типа и выделением пластического фронта. В работе [4] зарегистрировано затухание упругого предвестника из керамики оксида алюминия. Найдено, что уменьшение толщины от 3 до $0.25 \mathrm{~mm}$ привело к увеличению величины динамического предела упругости с 6.5 до $13 \mathrm{GPa}$ при комнатной температуре. Формирование зуба текучести в керамике из оксида алюминия начинается при температурах, превышающих $800 \mathrm{~K}$ в образцах толщиной менее $3 \mathrm{~mm}$. В отличие от пластичных сред для неупругого деформирования высокотвердых хрупких материалов характерны процессы локализации деформации и энергии растрескивания, которое может инициироваться даже при напряжениях несколько ниже предела упругости, дилатансионные и другие специфические эффекты. 
Ранее поведение керамики из карбида кремния в условиях ударного сжатия исследовалось в работах [5-10]. Было найдено, что с увеличением плотности керамики карбида кремния от 3.09 до $3.24 \mathrm{~g} / \mathrm{cm}^{3}$ ее динамический предел упругости возрастает от 8 до $16 \mathrm{GPa}$. В процессе сжатия при напряжениях выше динамического предела упругости имеет место значительное деформационное упрочнение. При разгрузке из ударно-сжатого состояния материал ведет себя как упругопластическое тело с сильным эффектом Баушингера [8]. С увеличением толщины образцов от 0.5 до $8.3 \mathrm{~mm}$ у реакционноспеченного карбида кремния не выявлено затухания упругого предвестника или других признаков релаксации напряжений [5]. В работах [11-13] предложены модели поведения керамики карбида кремния при высокоскоростном ударе, причем результаты компьютерного моделирования ударно-волновых явлений согласуются с экспериментальными данными.

Карбид бора обладает высокими механическими характеристиками, прежде всего твердостью, износостойкостью, высокими модулями упругости $[14,15]$. Кроме того, относительно низкая плотность в сочетании с высокими механическими характеристиками обусловливают широкое использование этого материала. Керамика на основе В4С применяется в качестве режущего инструмента, шлифовальных порошков, износостойких покрытий.

В настоящей работе для выявления особенностей высокоскоростного деформирования при упругопластическом переходе проведены измерения эволюции волны ударного сжатия в горячепрессованных керамиках карбида бора и карбида кремния в диапазоне толщин образца от 0.5 до $8 \mathrm{~mm}$.

\section{Материал и постановка экспериментов}

Образцы керамик для исследований изготавливались из двух типов тугоплавких соединений - карбида кремния и карбида бора. На данный момент наиболее освоенными технологиями получения высокоплотных керамических материалов на основе данных соединений являются методы горячего прессования и реакционного спекания [16-18]. В настоящей работе в качестве метода получения образцов был выбран метод горячего прессования, который в отличие от метода реакционного спекания позволяет получать однофазные материалы. При горячем прессовании карбида бора и карбида кремния основным механизмом уплотнения является пластическая деформация. Высокая температура и давление при горячем прессовании приводят к увеличению контактной поверхности частиц, интенсификации диффузионных процессов, что позволяет получать конечные материалы с минимальной пористостью.

В настоящей работе горячее прессование субмикронных порошков карбида бора и карбида кремния осуществлялось в графитовых пресс-формах при температу-
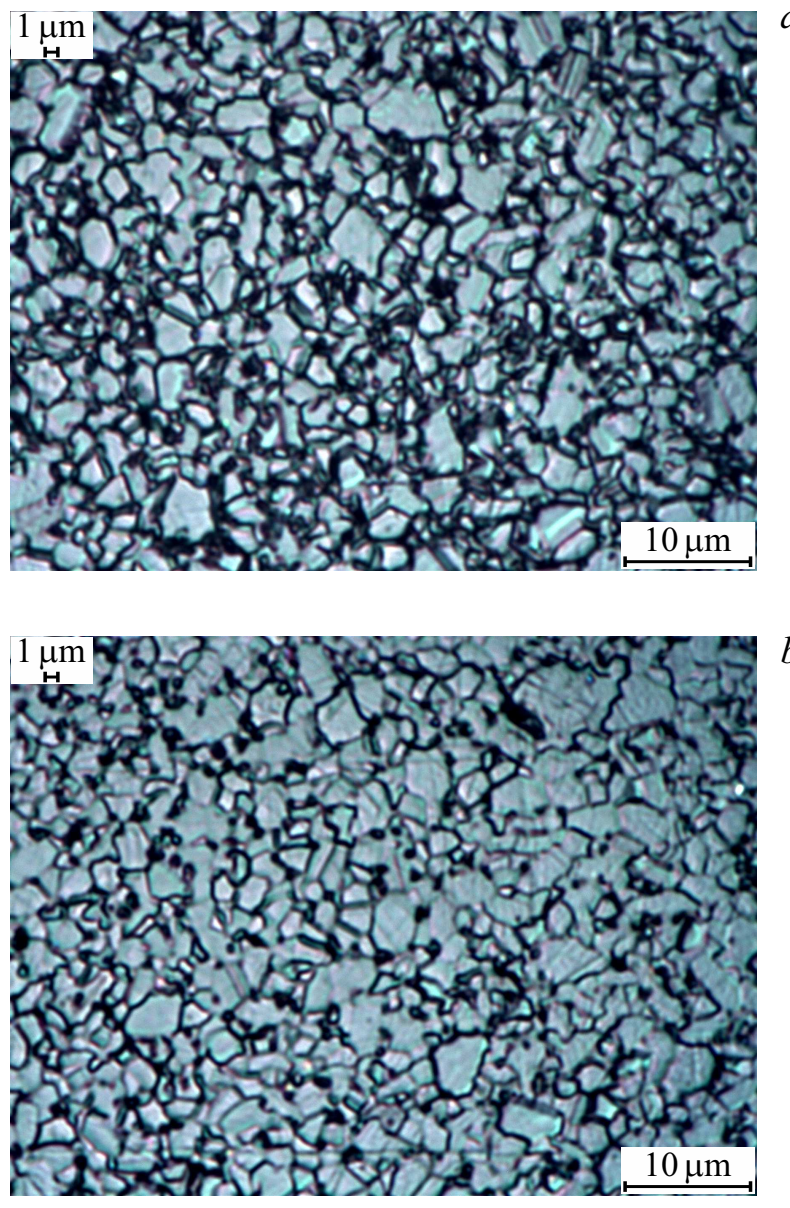

Рис. 1. Микроструктуры материалов после травления: $a$ $\mathrm{B}_{4} \mathrm{C} ; b-\mathrm{SiC}$. Масштаб линейки снизу $10 \mu \mathrm{m}$, сверху $-1 \mu \mathrm{m}$.

pe $2050^{\circ} \mathrm{C}$ и давлении $35 \mathrm{MPa} \mathrm{в} \mathrm{среде} \mathrm{аргона} \mathrm{на} \mathrm{горячем}$ прессе HP-W-125-FCT. Из полученных заготовок в виде дисков диаметром $180 \mathrm{~mm}$ и толщиной $8 \mathrm{~mm}$ изготавливались образцы требуемых геометрических размеров и толщины для изучения их свойств. Измерение толщины подготовленных к ударно-волновым экспериментам образцов проводилось с точностью $\pm 2 \mu \mathrm{m}$. Исследование физико-механических свойств проводилось по стандартизованным методикам. Предел прочности при трехточечном изгибе определяли на образцах размером $5 \times 5 \times 30 \mathrm{~mm}$ на испытательной машине „TEST-113100-Kn“" по формуле (ГОСТ 20019):

$$
\sigma_{f l x}=3 F L / 2 b h^{2},
$$

где $\sigma_{f l x}-$ прочность при изгибе $(\mathrm{MPa}) ; F-$ предельная нагрузка $(\mathrm{N}) ; L-$ расстояние между опорными цилиндрами $(\mathrm{mm}) ; b-$ ширина образца, измеряемая под прямым углом к высоте $(\mathrm{mm}) ; h-$ высота образца, параллельная направлению приложения нагрузки $(\mathrm{mm})$.

Определение твердости, микротвердости по Виккерсу и трещиностойкости проводили путем вдавливания в полированную поверхность образцов (фрагменты образ- 
Таблица 1. Физико-механические свойства исследованных материалов

\begin{tabular}{|c|c|c|c|}
\hline \multicolumn{2}{|c|}{ Параметр } & $\mathrm{B}_{4} \mathrm{C}$ & $\mathrm{SiC}$ \\
\hline \multicolumn{2}{|c|}{$\rho, \mathrm{g} / \mathrm{cm}^{3}$} & $2.52 \pm 0.01$ & $3.16 \pm 0.01$ \\
\hline \multicolumn{2}{|c|}{$H \nu^{5}, \mathrm{GPa}$} & $38.4 \pm 0.3$ & $22.4 \pm 0.3$ \\
\hline \multicolumn{2}{|c|}{$H \mu^{200}, \mathrm{GPa}$} & $41.3 \pm 2.4$ & $22.6 \pm 2.6$ \\
\hline \multicolumn{2}{|c|}{$K_{1 c}, \mathrm{MPa} \cdot \mathrm{m}^{1 / 2}$} & $2.5 \pm 0.1$ & $2.6 \pm 0.1$ \\
\hline \multicolumn{2}{|c|}{$E, \mathrm{GPa}$} & $458 \pm 4$ & $449 \pm 3$ \\
\hline \multicolumn{2}{|c|}{$\sigma_{f l x}, \mathrm{MPa}$} & $460 \pm 30$ & $420 \pm 30$ \\
\hline \multirow{2}{*}{ Размер пор, $\mu \mathrm{m}$} & Средний & 2.19 & 2.29 \\
\hline & Максимальный & 12.67 & 8.51 \\
\hline
\end{tabular}

цов после испытания на прочность) алмазного наконечника в форме правильной четырехгранной пирамиды на твердомере Falcon-508 и микротвердомере „ПМТ-

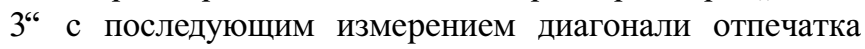
(в случае твердости, ГОСТ 9450) и длины трещины от центра отпечатка (в случае трещиностойкости согласно аттестованной метрологическим центром РОСНАНО методике № 09/0100302-2010/2012) по формулам:

$$
H=\left(1854 P_{H} / C^{2}\right),
$$

где $H-$ значение твердости в $\mathrm{GPa} ; P_{H}-$ нагрузка в N; $C$ - диагональ отпечатка в $\mathrm{m}$.

$$
K_{1 c}=0.073 P_{K} c^{-3 / 2},
$$

где $K_{1 c}$ - параметр трещиностойкости материала, $\mathrm{MPa} \cdot \mathrm{m}^{1 / 2} ; P_{K}$ - нагрузка в $\mathrm{g} ; c-$ длина трещины от центра отпечатка в $\mathrm{m}$.

Модуль упругости определяли методом вынужденных колебаний на приборе „Звук-130“ согласно ГОСТ 25095. Исследование микроструктуры полученных материалов осуществляли методами оптической микроскопии на материаловедческом микроскопе „Leica-DM-2500-M“ с использованием автоматического анализатора изображения „ВидеоТест-Структура 5.2“.

Микроструктуры горячепрессованных материалов после травления характеризуются присутствием зерен как изометрической, так и многогранной формы со средним размером частиц $5 \mu \mathrm{m}$ (рис. 1). Общая пористость керамики карбида бора не превышает $0.6 \%$, карбида кремния - $0.3 \%$. Измеренные физико-механические свойства исследованных материалов суммированы в табл. 1. Измеренное значение продольной скорости звука в карбиде бора составило $c_{l}=13.6 \pm 0.1 \mathrm{~km} / \mathrm{s}$, в карбиде кремния $-11.9 \pm 0.1 \mathrm{~km} / \mathrm{s}$. Для обеспечения максимальной точности измерения продольной скорости звука проводились на образцах толщиной $8 \mathrm{~mm}$.

Исходные образцы карбида бора и карбида кремния представляли собой плоскопараллельные пластины но- минальной толщиной $8,4,2,1$ и $0.5 \mathrm{~mm}$. Образцы вырезались из одной пластины алмазным диском с высокой точностью и затем подвергались шлифованию на алмазном круге. Нагружение образцов керамики карбида бора осуществлялось ударом алюминиевой пластины толщиной $10 \mathrm{~mm}$ или $2 \mathrm{~mm}$, разогнанной до скорости $2.6 \mathrm{~km} / \mathrm{s}$ или $1.8 \mathrm{~km} / \mathrm{s}$ соответственно с применением взрывных устройств [2]. Образцы керамики карбида кремния нагружались алюминиевым ударником толщиной $10 \mathrm{~mm}$ со скоростью $2.6 \mathrm{~km} / \mathrm{s}$. Во всех экспериментах нагружение проводилось через алюминиевый экран толщиной $2 \mathrm{~mm}$ для отсечения воздушной волны, образующейся перед летящим ударником.

B процессе нагружения образцов с помощью лазерного допплеровского измерителя скорости VISAR [19], имеющего временное разрешение $\sim 1 \mathrm{~ns}$, регистрировались профили скорости контактной поверхности $u_{p}(t)$ между образцом и водяным окном, либо окном из монокристаллического фторида лития. Отражение лазерного излучения в экспериментах с использованием водяного окна происходило от слоя алюминия толщиной несколько микрон, нанесенного на поверхность образца вакуумным напылением. При использовании окна из монокристаллического $\mathrm{LiF}$ алюминий напылялся на окно. Поперечные размеры образцов были достаточными для обеспечения условия одномерной деформации в течение всего времени регистрации.

\section{Результаты измерений}

На рис. 2 показаны измеренные профили скорости контактной поверхности $u_{p}(t)$ образцов керамики горячепрессованного карбида кремния на границе с водяным окном при ударе алюминиевой пластиной толщиной

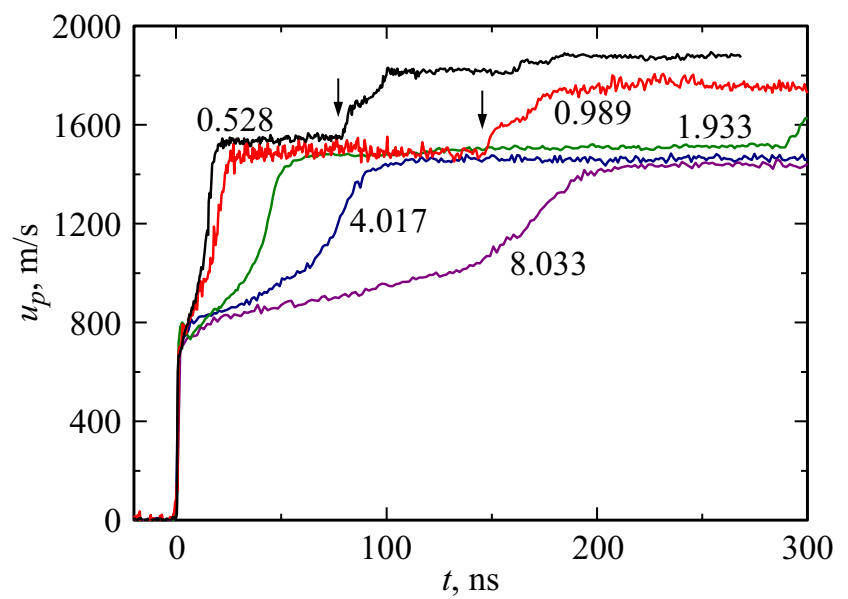

Рис. 2. Профили скорости контактной поверхности образцов керамики карбида кремния на границе с водяным окном толщиной от 0.5 до $8 \mathrm{~mm}$ при ударе $10 \mathrm{~mm}$ алюминиевой пластиной со скоростью $2.6 \mathrm{~km} / \mathrm{s}$ через алюминиевый экран толщиной $2 \mathrm{~mm}$. Цифрами указаны толщины образцов в $\mathrm{mm}$. Стрелками указан момент выхода на контактную поверхность переотраженной волны сжатия. 


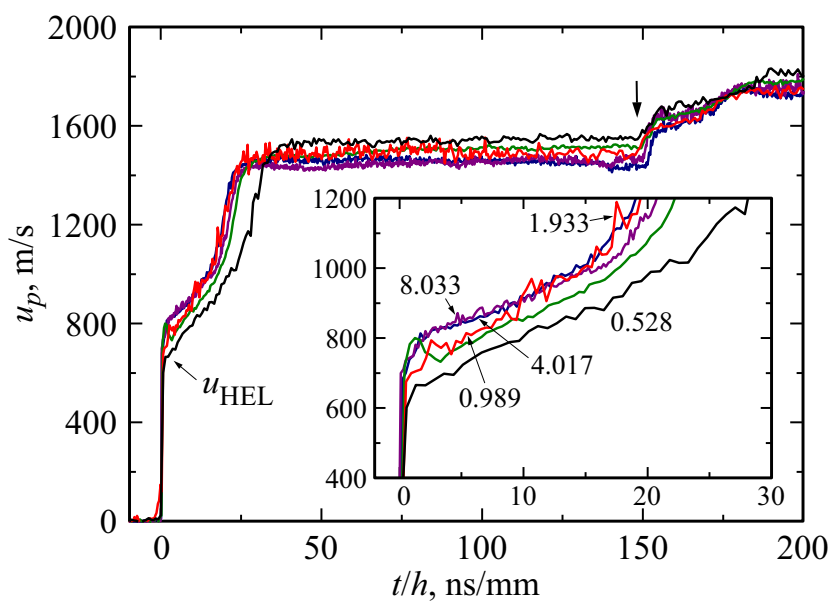

Рис. 3. Профили скоростей контактной поверхности образцов керамики карбида кремния, представленные на рис. 2, в нормированных координатах по времени. Цифрами указаны толщины образцов в $\mathrm{mm}$. Стрелкой указан выход на контактную поверхность переотраженной волны сжатия.

$10 \mathrm{~mm}$ со скоростью $2.6 \mathrm{~km} / \mathrm{s}$, что соответствует максимальному давлению в образце $\sim 34 \mathrm{GPa}$. В общих чертах профили волн сжатия подобны полученным ранее для горячепрессованной [10], поликристаллической [12] и для реакционноспеченной керамики $\mathrm{SiC}[5,20]$. На волновых профилях регистрируется второй подъем скорости, указанный на рис. 2 стрелками, вызванный переотражением волны разрежения от поверхности экран-образец. Так как динамический импеданс керамики $\mathrm{SiC}$ выше, чем динамический импеданс алюминиевого экрана, отражение волны разрежения происходит с изменением ее знака, в результате переотраженная волна является волной сжатия. В лагранжевых координатах средние значения скорости фронтов волны разрежения, распространяющейся по сжатому материалу, и волны сжатия в разгруженном материале находятся в диапазоне $13.25 \pm 0.05 \mathrm{~km} / \mathrm{s}$, что несколько превышает измеренную продольную скорость звука при нулевом давлении. Данный факт косвенно свидетельствует о том, что материал не претерпевал разрушения при давлениях, превышающих динамический предел упругости в процессе одномерного сжатия и последующей разгрузки, поскольку наличие трещин оказывает значительное влияние на скорость распространения волновых возмущений.

Величина динамического предела упругости $\sigma_{\mathrm{HEL}}$ определяется путем восстановления параметров ударных волн в керамике карбида кремния по измеренным значениям массовой скорости на границе между образцом керамики и водяным окном. Для анализа волновых взаимодействий использовались ударная адиабата окна и волновой луч для упругой части адиабаты керамики карбида кремния в виде $P=\rho_{0} c_{l} u$, где $P$ - давление, $\rho_{0}-$ начальная плотность, $u-$ значение массовой скорости. Из измеренного профиля контактной поверхности керамики $\mathrm{SiC}$ определялось значение массовой скорости $u_{\mathrm{HEL}}$ соответствующее упругопластическому переходу. Измеренные значения давления и массовой скорости на входе в „окно“ лежат на ударной адиабате воды и соответствуют состояниям в отраженных волнах с изменением знака нагрузки. Наклон волнового луча упругой части адиабаты керамики карбида кремния выше, чем наклон адиабаты воды, что свидетельствует об отражении ударной волны в керамике карбида кремния в виде волны разрежения от границы образец-окно. По пересечению волнового луча упругой части адиабаты керамики карбида кремния и волнового луча упругой части карбида кремния, выходящего из точки $u_{\mathrm{HEL}}$ на адиабате воды, соответствующего разгрузке, определялось искомое значение $\sigma_{\mathrm{HEL}}$ керамики карбида кремния.

Из непосредственного сопоставление профилей $u_{p}(t)$ на рис. 2 видно, что напряжение сжатия за фронтом упругого предвестника волны сжатия незначительно уменьшается с уменьшением толщины образца. Представленные на рис. 3 нормированные волновые профили, в которых вместо времени $t$ используется отношение $t / h$, где $h$ - толщина образца, подтверждают уменьшения величины $u_{\mathrm{HEL}}$ с уменьшением толщины образца. Сопоставление нормированных волновых профилей на рис. 3 обнаруживает эту закономерность в их положении друг относительно друга с небольшими отклонениями, связанными, по-видимому, с небольшими вариациями плотности и распределением пор по толщине образца. Подтверждением этого являются эксперименты с образцами толщиной 0.987 и $0.528 \mathrm{~mm}$. В отличие от более толстых образцов в них регистрируются значительно меньшие значения скорости второй пластической волны. Выход на контактную поверхность отраженной волны сжатия от алюминиевого экрана (рис. 3) происходит в приблизительно один момент времени, что свидетельствует о постоянстве времени реверберации волны сжатия между экраном и контактной поверхностью, не зависящем от толщины образца. Определенные значения массовой скорости $u_{\mathrm{HEL}}$, лежащие на адиабате воды и рассчитанные по ним значения $\sigma_{\mathrm{HEL}}$, представлены в табл. 2. На вкладке рис. 3 видно, что регистрируемые значения массовой скорости $u_{\mathrm{HEL}}$ у образцов толщиной 8.033 и $4.017 \mathrm{~mm}$ близки, у остальных образцов значение $u_{\mathrm{HEL}}$ ниже.

Полученное значение динамического предела упругости для образца керамики толщиной $8 \mathrm{~mm}$ составляет $15 \pm 0.1 \mathrm{GPa}$, что хорошо согласуется с ранее выполненными измерениями для различных по плотности, структуре и методам изготовления керамик карбида кремния [5-10,20].

На рис. 4 показаны измеренные профили скорости контактной поверхности образцов керамики горячепрессованного карбида бора толщиной от 0.5 до $8 \mathrm{~mm}$ на границе с водяным окном при ударе алюминиевой пластиной толщиной $10 \mathrm{~mm}$ со скоростью $2.6 \mathrm{~km} / \mathrm{s}$, что соответствует максимальному давлению в образце около $32 \mathrm{GPa}$. Волновые профили демонстрируют выход на поверхность упругого предвестника с резким скачком 
Таблица 2. Определенные значения массовой скорости $u_{\mathrm{HEL}}$ и рассчитанные значения $\sigma_{\mathrm{HEL}}$ для образцов $\mathrm{SiC}$ различных толщин $h$

\begin{tabular}{c|c|c}
\hline$h, \mathrm{~mm}$ & $u_{\mathrm{HEL}}, \mathrm{m} / \mathrm{s}$ & $\sigma_{\mathrm{HEL}}, \mathrm{GPa}$ \\
\hline 8.033 & 742 & 15.1 \\
8.030 & 736 & 14.9 \\
4.017 & 714 & 14.5 \\
1.933 & 690 & 14.0 \\
0.989 & 706 & 14.4 \\
0.987 & 599 & 12.1 \\
0.528 & 630 & 12.7
\end{tabular}

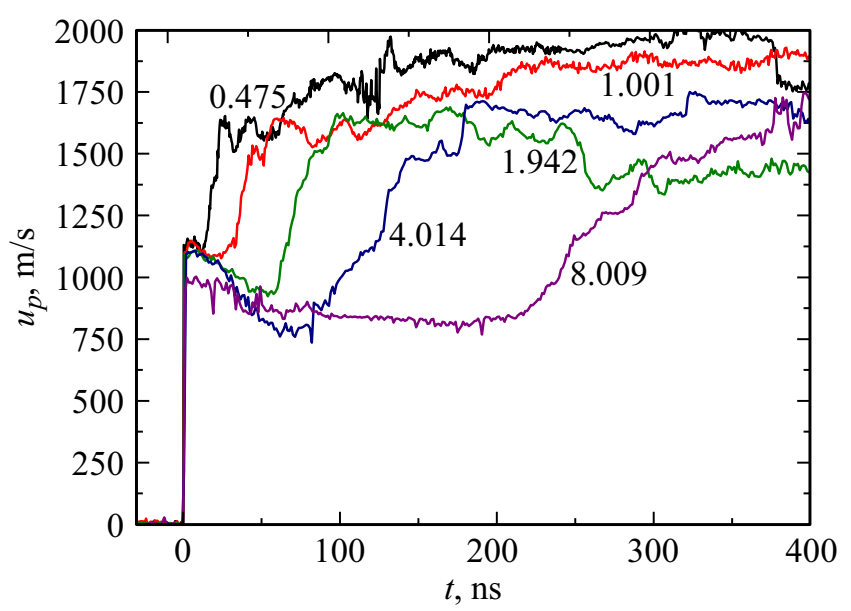

Рис. 4. Профили скорости контактной поверхности керамики карбида бора на границе с водяным окном толщиной от 0.5 до $8 \mathrm{~mm}$ при ударе $10 \mathrm{~mm}$ алюминиевой пластиной со скоростью $2.6 \mathrm{~km} / \mathrm{s}$ через алюминиевый экран толщиной $2 \mathrm{~mm}$. Цифрами указаны толщины образцов в миллиметрах.

напряжения до величины динамического предела упругости и последующей релаксацией напряжений за фронтом упругого предвестника. Видно, что с увеличением толщины образца релаксация напряжений происходит глубже, когда толщины образцов не превышают $4 \mathrm{~mm}$. У образца толщиной $8 \mathrm{~mm}$ релаксация напряжений выражена не так отчетливо. В работе [21] получены профили свободной поверхности для реакционноспеченного карбида бора, где релаксация напряжений за фронтом упругого предвестника не наблюдается, что, по-видимому, связано со структурой материала. Далее регистрируется выход второй пластической волны. Время выхода пластической волны в каждом эксперименте согласуется по времени с толщиной образца, что свидетельствует об одинаковой скорости распространения второй пластической волны.

Полученные профили скорости контактной поверхности керамики карбида бора содержат нерегулярные осцилляции в отличие от волновых профилей для керамики карбида кремния, которые имеют регулярный характер и хорошо воспроизводимы. Сильные осцилляции скорости контактной поверхности для керамики карбида бора, очевидно, есть результат значительной гетерогенности неупругой деформации. Для керамики карбида кремния регистрируется монотонное нарастание параметров за фронтом упругого предвестника с плавным переходом в пластическую волну сжатия, в то время как в случае керамики карбида бора имеет место значительный спад параметров за фронтом упругого предвестника. В отличие от керамики карбида кремния в ней не регистрируется переотражение волны сжатия от алюминиевого экрана, что свидетельствует о растрескивании образца под действием давления.

Для подтверждения релаксационного поведения керамики карбида бора при ударном сжатии были проведены дополнительные эксперименты с окном из монокристаллического фторида лития при меньшем давлении. На рис. 5 показаны измеренные профили скорости контактной поверхности образцов карбида бора толщиной от 0.5 до $8 \mathrm{~mm}$ при ударе алюминиевой пластиной толщиной $2 \mathrm{~mm}$ со скоростью $1.8 \mathrm{~km} / \mathrm{s}$ через алюминиевый экран толщиной $2 \mathrm{~mm}$, что соответствует максимальному давлению ударного сжатия $24 \mathrm{GPa}$. В общих чертах полученные результаты для опытов при меньшем давлении совпадают с результатами, полученными в экспериментах с водяным окном. Волновые профили демонстрируют выход на поверхность упругого предвестника с резким скачком напряжения до величины динамического предела упругости, после чего фиксируется релаксация напряжений за фронтом упругого предвестника. Профили контактной поверхности, как и при давлении $32 \mathrm{GPa}$, также насыщены сильными осцилляциями скорости, связанными с гетерогенностью неупругого деформирования и растрескиванием материала.

Значения динамического предела упругости керамики карбида бора рассчитывались аналогично тому, как это делалось для керамики карбида кремния. Результаты рас-

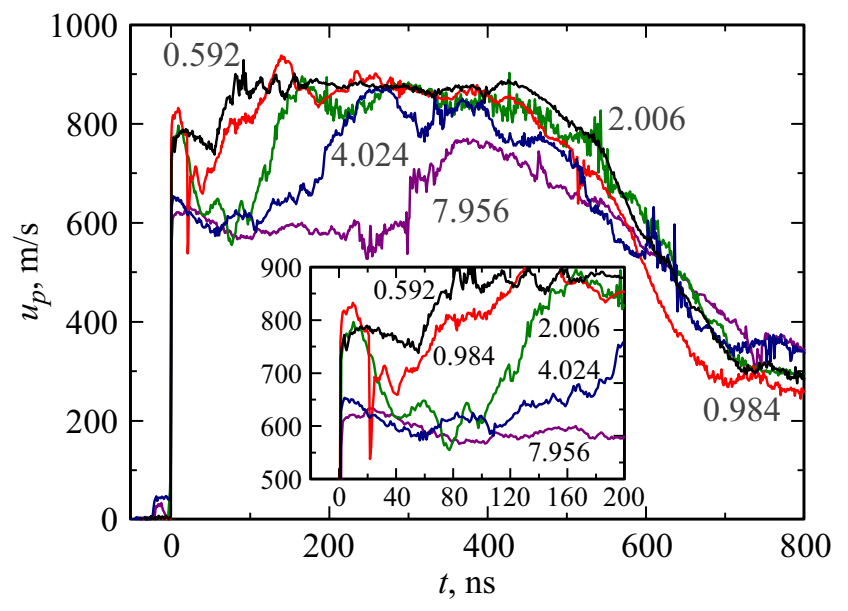

Рис. 5. Профили скорости контактной поверхности образцов керамики карбида бора толщиной от 0.5 до $8 \mathrm{~mm}$ на границе с окном из монокристаллического $\mathrm{LiF}$ при ударе $2 \mathrm{~mm}$ алюминиевой пластиной со скоростью $1.8 \mathrm{~km} / \mathrm{s}$ через алюминиевый экран толщиной $2 \mathrm{~mm}$. Цифрами указаны толщины образцов в миллиметрах. 


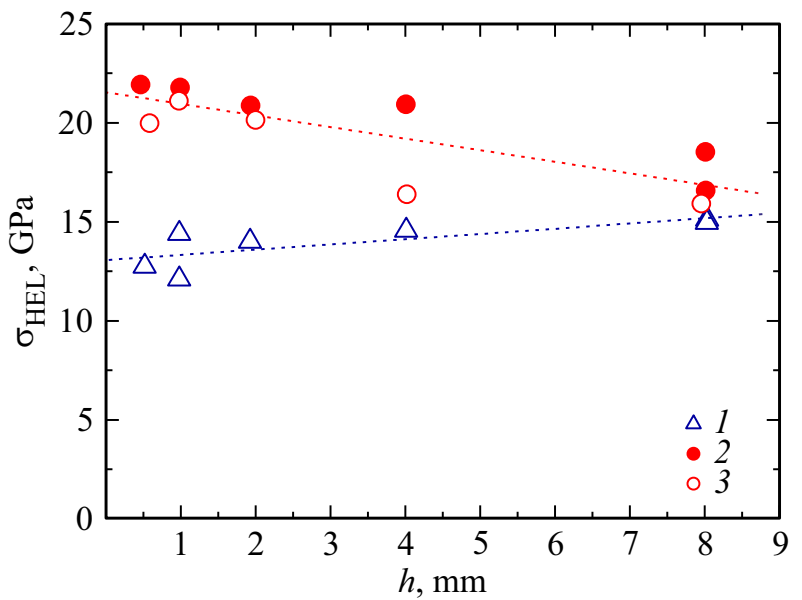

Рис. 6. Зависимость динамического предела упругости керамик $\mathrm{SiC}$ и $\mathrm{B}_{4} \mathrm{C}$ от толщины. 1 - карбид кремния, 2 - карбид бора при максимальном давлении $32 \mathrm{GPa}, 3$ - карбид бора при максимальном давлении $24 \mathrm{GPa}$.

Таблица 3. Определенные значения массовой скорости $u_{\mathrm{HEL}}$ и рассчитанные значения $\sigma_{\mathrm{HEL}}$ для образцов $\mathrm{B}_{4} \mathrm{C}$ различных толщин $h$ при двух значениях максимального давления

\begin{tabular}{l|c|c}
\hline$h, \mathrm{~mm}$ & $u_{\mathrm{HEL}}, \mathrm{m} / \mathrm{s}$ & $\sigma_{\mathrm{HEL}}, \mathrm{GPa}$ \\
\hline \multicolumn{3}{c}{$32 \mathrm{GPa}$} \\
\hline 0.475 & 1148 & 21.9 \\
1.001 & 1142 & 21.8 \\
1.942 & 1098 & 20.8 \\
4.014 & 1100 & 20.9 \\
8.009 & 982 & 18.5 \\
8.011 & 883 & 16.5 \\
\hline \multicolumn{3}{|c}{} \\
\hline 7.956 & $24 \mathrm{GPa}$ & 15.9 \\
2.006 & 632 & 20.1 \\
0.984 & 793 & 21.1 \\
4.024 & 830 & 16.4 \\
0.592 & 652 & 19.9
\end{tabular}

чета динамического предела упругости при различных давлениях представлены в табл. 3. Полученное значение динамического предела упругости горячепрессованной керамики карбида бора образца толщиной $8 \mathrm{~mm}$ coставило $\sigma_{\mathrm{HEL}}=17.2 \pm 1.3 \mathrm{GPa}$, что также соответствует значениям динамического предела упругости различных керамик на основе карбида бора [8,21-29], анализ этих данных показывает, что с увеличением плотности керамики с 2.1 до $2.52 \mathrm{~g} / \mathrm{cm}^{3}$ динамический предел упругости $\mathrm{B}_{4} \mathrm{C}$ возрастает с 8 до $19.5 \mathrm{GPa}$.

На рис. 6 суммированы полученные значения динамического предела упругости горячепрессованных керамик карбида бора и карбида кремния в зависимости от толщины образца. Видно, что с ростом толщины образца значение $\sigma_{\text {HEL }}$ для керамики карбида бора незначительно падает, в то время как для керамики карбида кремния наблюдается его незначительный рост. Уменьшение $\sigma_{\mathrm{HEL}}$ для керамики карбида кремния с уменьшением толщины образца, по-видимому, связано с имеющейся пористостью и возможным неоднородным распределением пор по толщине образца. Еще одной возможной причиной такого результата экспериментов с тонкими образцами керамики карбида кремния может быть технология тонких образцов - долговременное шлифование до нужной толщины могло повлиять на концентрацию дефектов в приповерхностном слое. В работе [5] эксперименты с реакционноспеченной керамикой карбида кремния толщиной от 0.5 до $8.3 \mathrm{~mm}$ не обнаруживают затухания упругого предвестника и показывают, что эволюция волны сжатия соответствует простой волне. Образцы реакционноспеченной керамики карбида кремния, исследованные в этой работе, вырезались электроэрозионным методом практически без какого-либо влияния на их внутреннюю структуру.

Затухание упругого предвестника с увеличением толщины для керамики карбида бора регистрируется как при максимальном давлении $32 \mathrm{GPa}$, так и при $24 \mathrm{GPa}$. При этом в экспериментах при $32 \mathrm{GPa}$ регистрируются более высокие значения динамического предела упругости при тех же толщинах образцов. Заметный разброс этих данных может быть связан с наличием пористости и крупных пор в объеме образца.

\section{Заключение}

Измерения эволюции профилей скорости контактной поверхности в образцах горячепрессованных керамик карбида бора и карбида кремния толщиной от 0.5 до $8 \mathrm{~mm}$ показали затухание упругого предвестника в карбиде бора и незначительный аномальный рост упругого предвестника с увеличением толщины у карбида кремния. Керамика на основе карбида бора демонстрирует признаки релаксации напряжений за фронтом упругого предвестника, тогда как у керамики карбида кремния признаков релаксации напряжений за фронтом упругого предвестника не обнаружено, а нарастание параметров за фронтом упругой волны сжатия связано, очевидно, с деформационным упрочнением [30]. Анализ волновых профилей показал, что при превышении динамического предела упругости керамика карбида кремния сохраняет свою внутреннюю структуру неповрежденной, а керамика карбида бора растрескивается. Измеренные значения динамического предела упругости у образцов толщиной $8 \mathrm{~mm}$ карбида кремния составили $\sigma_{\mathrm{HEL}}=15 \pm 0.1 \mathrm{GPa}$, для карбида бора $\sigma_{\mathrm{HEL}}=17.2 \pm 1.3 \mathrm{GPa}$; эти величины с учетом плотности керамики хорошо согласуются с известными литературными данными.

Работа выполнена по проекту гос. задания, № гос. регистрации 0089-2014-0016, и в рамках Программы Президиума РАН „Конденсированное вещество и плазма при высоких плотностях энергии“ в рамках научного направления „Быстрые физико-химические превращения и разрушение твердых тел и жидкостей“. 


\section{Список литературы}

[1] Гаршин А.П., Гропянов В.М., Зайщев Г.П., Семенов С.С. Керамика для машиностроения. М.: Научтехлитиздат, 2003. $384 \mathrm{c}$.

[2] Канель Г.И., Разоренов С.В., Уткин А.В., Фортов В.Е. Ударно-волновые явления в конденсированных средах. М.: Янус-К, 1996. 407 с.

[3] Савельева Н.В., Баяндин Ю.В., Савиных А.С., Гаркушин Г.В., Ляпунова Е.А., Разоренов С.В., Наймарк О.Б. // Письма в ЖТФ. 2015. Т. 41. Вып. 12. C. 32-39. [Saveleva N.V., Bayandin Yu.V., Savinykh A.S., Garkushin G.V., Lyapunova E.A., Razorenov S.V., Naimark O.B. // Technic. Phys. Lett. 2015. Vol. 41. N 6. P. $579-582$.

DOI: $10.1134 / \mathrm{S} 1063785015060292$

[4] Zaretsky E.B. // J. Appl. Phys. 2013. Vol. 114. P. 183518. DOI: $10.1063 / 1.4830014$

[5] Савиных А.С., Канель Г.И., Разоренов С.В., Румянцев В.И. // ЖТФ. 2013. Т. 83. Вып. 7. С. 43-47. [Savinykh A.S., Kanel G.I., Razorenov S.V., Rumyantsev V.I. // Tech. Phys. 2013. Vol. 58. N 7. P. 973-977.] DOI: $10.1134 / \mathrm{S} 1063784213070207$

[6] Bourne N.K., Millett J.C.F., Pickup I. // J. Appl. Phys. 1997. Vol. 81. N 6. P. 6019-6023. https://doi.org/10.1063/1.363967

[7] Feng R., Gupta Y.M., Yuan G. In: Shock compression of condensed matter-1997. / Eds. S.C. Schmidt, D.P. Dandekar, J.W. Forbes. NY:: AIP CP 483. 1998. P. 483-488. https://doi.org/10.1063/1.55551

[8] Kipp M.E., Grady D.E. In: Shock compression of condensed matter-1989. / Eds. S.C. Schmidt, J.N. Johnson, L.W. Davison. Amsterdam: North-Holland, 1990. P. 377-380.

[9] Gust W.H., Holt A.C., Royce E.B. // J. Appl. Phys. 1973. Vol. 44. N 2. P. 550-560. https://doi.org/10.1063/1.1662224

[10] Vogler T.J., Reinhart W.D., Chhabildas L.C. // J. Appl. Phys. 2006. Vol. 99. P. 023512. https://doi.org/10.1063/1.2159084

[11] Rajendran A.M., Grove D.J. // Int. J. Impact Eng. 1996. Vol. 18. N 6. P. 611-631. https://doi.org/10.1016/0734743X $(96) 89122-6$

[12] Feng R., Raiser G.F., Gupta Y.M. // J. Appl. Phys. 1996. Vol. 79. N 3. P. $1378-1387$. https://doi.org/10.1063/1.361036

[13] Holmquist T.J., Johnson G.R. // J. Appl. Phys. 2005. Vol. 97. P. 093502. https://doi.org/10.1063/1.1881798

[14] Th'evenot F. // J. Eur. Ceram. Soc. 1990. Vol. 6. N 4. P. 205-225. https://doi.org/10.1016/0955-2219(90)90048-K

[15] Domnich V., Reynaud S., Haber R.A., Chhowalla M. // J. Am. Ceram. Soc. 2011. Vol. 94. N 11. P. 3605-3628. DOI: $10.1111 / \mathrm{j} .1551-2916.2011 .04865 . \mathrm{x}$

[16] Suri A.K., Subramanian C., Sonber J.K., T.S.R.Ch. // Murthy, Intern. Mater. Rev. 2010. Vol. 55. N 1. P. 4-40. https://doi.org/10.1179/095066009X12506721665211

[17] Skarpeid H. In: Materials Technology-Norwegian University of Science and Technology (NTNU), Trondheim, Norway, 2017. P. 102.

[18] Гнесин Г.Г., Румянцев В.И. Актуальные проблемы технологии производства современных керамических материалов: сборник трудов научного семинара. СПб.: Изд-во политех. ун-та, 2015. С. 17-34.

[19] Barker L.M., Hollenbach R.E. // J. Appl. Phys. 1972. Vol. 43. N 11. P. 4669-4675. https://doi.org/10.1063/1.1660986

[20] Гаркушин Г.В., Разоренов С.В., Румянцев В.И., СавиHыx A.C. // Известия РАН. Механика твердого тела. 2014. Вып. 6. C. 19-26. [Garkushin G.V., Razorenov S.V., Rumyantsev V.I., Savinykh A.S. // Mechan. Sol. 2014. Vol. 49. N 6. P. 616-622.] DOI: 10.3103/S0025654414060028
[21] Савиных А.С., Гаркушин Г.В., Разоренов С.В., Румянщев В.И. // ЖТФ. 2015. Т. 85. Вып. 6. С. 77-82. [Savinykh A.S., Garkushin G.V., Razorenov S.V., Rumyantsev V.I. // Tech. Phys. 2015. Vol. 60. N 6. P. 863-868.] DOI: $10.1134 /$ S1063784215060249

[22] Winkler W.D., Stilp A.J. In: Shock compression of condensed matter-1991. / Eds. S.C. Schmidt, R.D. Dick, J.W. Forbes, D.G. Tasker. Amsterdam: North-Holland, 1992. P. 475-478. https://doi.org/10.1016/B978-0-444-89732-9.50108-4

[23] Savinykh A.S., Kanel G.I., Razorenov S.V., Rajendran A. In: Shock compression of condensed matter-2005. / Eds. M.D. Furnish, M. Elert, T.P. Russell, C.T. White. AIP CP 845. 2006. P. 888-891. https://doi.org/10.1063/1.2263464

[24] Brar N.S., Rosenberg Z., Bless S.J. In: Shock Compression of Condensed Matter-1991. / Eds. S.C. Schmidt, R.D. Dick, J.W. Forbes, D.G. Tasker. Amsterdam: North-Holland, 1992. P. 467-470. https://doi.org/10.1016/B978-0-444-897329.50106-0

[25] Gust W.H., Royce E.B. // J. Appl. Phys. 1971. Vol. 42. N 1. P. 276-295. https://doi.org/10.1063/1.1659584

[26] Grady D.E. In: High-Pressure Science and Technology-1993. / Eds. S.C. Schmidt, J.W. Shaner, G.A. Samara, M. Ross. NY: AIP CP 309, 1994. P. 741-744. https://doi.org/10.1063/1.46206

[27] Hayun S., Frage N., Dariel M.P., Zaretsky E. In: Shock Compression of Condensed Matter-2007. / Eds. M. Elert, M.D. Furnish, R. Chau, N. Holmes, J. Nguyen. AIP CP 955, 2007. P. 747-750. https://doi.org/10.1063/1.2833227

[28] Zhang Y., Mashimo T., Uemura Y., Uchino M., Kodama M., Shibata K., Fukuoka K., Kikuchi M., Kobayashi T., Sekine T. // J. Appl. Phys. 2006. Vol. 100. P. 113536. https://doi.org/10.1063/1.2399334

[29] Vogler T.J., Reinhart W.D., Chhabildas L.C. // J. Appl. Phys. 2004. Vol. 95. N 8. P. 4173-4183. https://doi.org/10.1063/1.1686902

[30] Kanel G.I., Razorenov S.V., Fortov V.E. Shock Wave Phenomena and the Properties of Condensed Matter. NY: Springer, 2004. $321 \mathrm{p}$. 